\title{
Development and Validation of a Hopkinson Bar for Hazardous Materials
}

\author{
R.M. Quinn ${ }^{1}$ - L.H. Zhang ${ }^{2}$ - M.J. Cox ${ }^{3}$ - D. Townsend ${ }^{2}$ - T. Cartwright ${ }^{3}$ - G. Aldrich-Smith ${ }^{3}$ - P.A. Hooper ${ }^{1}$. \\ J.P. Dear $^{1}$ (1)
}

Received: 22 April 2020 / Accepted: 20 July 2020 / Published online: 18 August 2020

(C) The Author(s) 2020

\begin{abstract}
Background There are a variety of approaches that can be employed for Hopkinson bar compression testing and there is no standard procedure.
\end{abstract}

Objectives A Split-Hopkinson pressure bar (SHPB) testing technique is presented which has been specifically developed for the characterisation of hazardous materials such as radioactive metals. This new SHPB technique is validated and a comparison is made with results obtained at another laboratory.

Methods Compression SHPB tests are performed on identical copper specimens using the new SHPB procedures at Imperial College London and confirmatory measurements are performed using the well-established configuration at the University of Oxford. The experiments are performed at a temperature of $20^{\circ} \mathrm{C}$ and $200{ }^{\circ} \mathrm{C}$. Imperial heat the specimens externally before being inserted into the test position (ex-situ heating) and Oxford heat the specimens whilst in contact with the pressure bars (in-situ heating). For the ex-situ case, specimen temperature homogeneity is investigated both experimentally and by simulation.

Results Stress-strain curves were generally consistent at both laboratories but sometimes discrepancies fell outside of the inherent measurement uncertainty range of the equipment, with differences mainly attributed to friction, loading pulse shapes and pulse alignment techniques. Small metallic specimens are found to be thermally homogenous even during contact with the pressure bars.

Conclusion A newly developed Hopkinson bar for hazardous materials is shown to be effective for characterising metals under both ambient and elevated temperature conditions.

Keywords Split Hopkinson bar · Non-ambient · Miniaturised · Copper · Compression · Hazardous · Comparison

\section{Background and Objectives}

High strain rate experimental data is required to calibrate material models which describe the behaviour of dynamic processes. Experimental data should be collected in a robust, systematic and reliable way for high confidence modelling. Quasi-static testing is well understood and controlled by ISO and ASTM test standards, and measurement uncertainty budgets have been developed, for example, National Physics Laboratory TENSTAND.

J.P. Dear

j.dear@ic.ac.uk

Extended author information available on the last page of the article.
The compression split-Hopkinson pressure bar (SHPB) test is not subject to any agreed standards regarding the operation or design of the apparatus [1]. This leads to an unknown degree of variance in results attained by different laboratories. It is not always easy to tell whether differences are physical or methodological, even for materials as simple as fully annealed pure copper [2]. The measured flow stress is known to be influenced by factors which include specimen size and specimen aspect ratio [3], interfacial friction $[4,5]$ and data processing/interpretation techniques [6]. A recent review of frictional and inertial effects on the Hopkinson bar test is provided by Siviour and Walley [7]. The bar diameter and length is also important as the pressure wave undergoes a process known as dispersion; whereby different frequency components exhibit different propagation velocities, resulting in a pressure wave whose form is evolving with respect to time $[8,9]$. 
In this study, a Hopkinson bar apparatus which incorporates novel design features to tackle the unique problems associated with evaluating radioactive, or otherwise hazardous materials, is presented in detail. This new system is validated against another more established Hopkinson bar system at the Impact Engineering Laboratory, University of Oxford. The design, operating procedures and data processing methodologies of the University of Oxford system differ quite considerably from the new semi-automated apparatus at Imperial College. Both laboratories aimed to evaluate the material at the same target strain rate of $3000 \mathrm{~s}^{-1}$ and at the same temperatures. Tests were performed on a simple material; high purity, annealed copper.

In addition to describing and validating the newly developed procedures, this study aims to provide some useful insight into the inter-laboratory variance which might be expected in Hopkinson bar results. Another study has compared Hopkinson bar data obtained at different laboratories with identical materials [10]. This other study, which compared room temperature data only, found inter-laboratory variance in the measured flow stress of up to $15.9 \%$.

In this work, comparative tests were performed both at an ambient temperature of $20^{\circ} \mathrm{C}$, and at $200^{\circ} \mathrm{C}$. Higher temperature comparisons were not practical using the setup at Oxford, but further non-comparative tests were performed at Imperial at a temperature of $500{ }^{\circ} \mathrm{C}$ Each laboratory took a different approach to non-ambient testing. One laboratory performed in-situ heating of the specimen, where the specimen was heated whilst in contact with the pressure bars [11-14] and the other laboratory performed ex-situ heating - where the specimen was heated prior to contacting the pressure bars [1519]. Both approaches have limitations which are discussed.

\section{In-situ vs ex-situ specimen heating}

The in-situ method is the more common approach due to the simplicity of the apparatus. The dominant issue is the temperature inhomogeneity introduced into the pressure bars in the course of heating the specimen. The SHPB test exploits the predictable nature of stress wave propagation through uniform elastic cylinders - the inhomogeneity introduces non-uniform elastic behaviour which corrupts the pressure waves traversing their length [20]. It is possible to perform a correction to account for pressure wave distortion if the temperature gradient in the bars is known [21, 22], but this is often neglected, as it is in this work. Other researchers have used pressure bars made from materials with elastic properties that are relatively constant with respect to temperature, such as Inconel 718 [23]. Using the in-situ approach the testing temperature is limited due to the thermal softening of the pressure bars. Walley suggests this limit is around $600{ }^{\circ} \mathrm{C}$ [20]. A key advantage of the in-situ method is the uniformity of the specimen temperature.
The ex-situ method requires more complicated apparatus, but thermal homogeneity in the pressure bars is retained. The dominant issue is premature specimen cooling and there are concerns about specimen temperature inhomogeneity. Kuokkala et al [17] have developed a pneumatically actuated pressure bar system which is capable of performing tests with a specimen-bar contact time of 50-100 ms, which they claim almost entirely avoids any specimen cooling. This is in good agreement with our investigations. It is, however, argued in this work that a longer specimen-bar contact time is tolerable for smaller metallic specimens as the temperature within the specimen is almost homogeneous even during rapid cooling. It is important to know the specimen cooling rate as a function of the starting temperature so that the cooling can be accounted for. A procedure for determining this is outlined later.

\section{Materials}

The material used in this study is C103 high purity oxygen free copper. It has a specification of $99.95 \%$ purity with the main impurity being lead. It was received as a $3.19 \mathrm{~mm}$ diameter wrought rod which was sourced from Smiths Metals Limited UK and was annealed for 4 hours at $500{ }^{\circ} \mathrm{C}$ before being quenched in water. A reactive foil wrapping was used to reduce oxidation during the annealing process. The specimens were fully annealed so that differences attributable to the rate of specimen heating prior to testing would be mitigated.

Copper was chosen as its been well characterised by other researchers and therefore was ideal for validating new techniques. It was also considered to be an extreme test-case for ex-situ non-ambient SHPB testing. It was presumed to have fast cooling rate relative to other metals due to the high thermal conductivity of the material.

Electron Backscatter Diffraction (EBSD) was performed to verify the microstructure. An equiaxed grain structure normal to the length of the wrought rod is apparent with a grain size in the order of $25 \mu \mathrm{m}$ (see Fig. 1). Preferred orientation parallel to the length of the rod is evident and is consistent with a wrought product. The specimens used were $3.19 \mathrm{~mm}$ (diameter) by $3 \mathrm{~mm}$ (height) right cylinders with faces that were planar to within $0.01 \mathrm{~mm}$. This is an advised tolerance for SHPB testing of metals [1].

\section{Experimental procedure}

The classical SHPB test entails sandwiching a cylindrical specimen between two long cylinders known as pressure bars. The pressure bars are impacted at one end by a third cylinder called a striker bar. The impact imparts a 

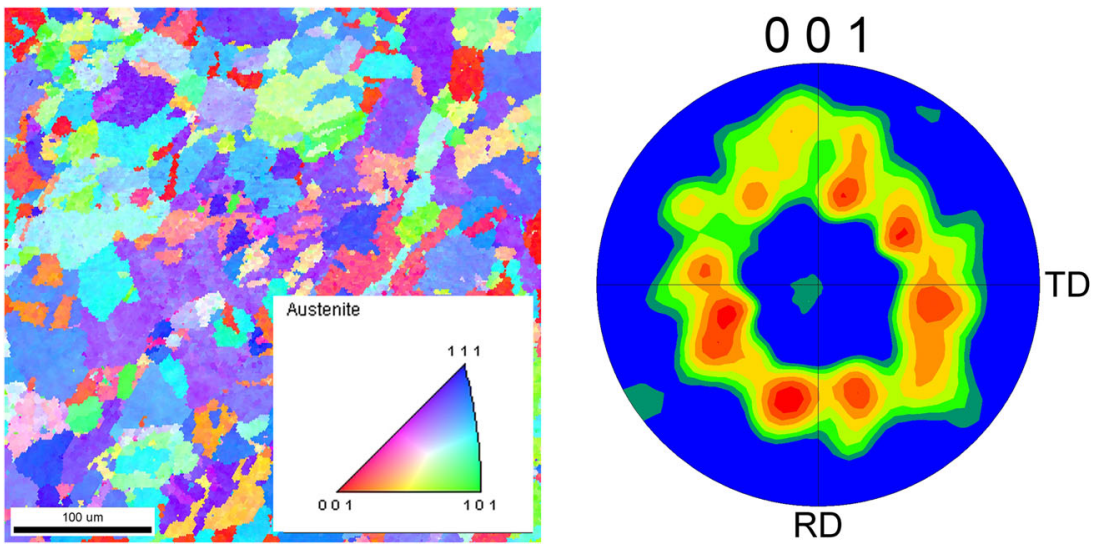

Texture Name: Binned: Size $=5.0, \mathrm{H} M=5.0$

Calculation Method: Discrete Binning

Bin Size: $5.0^{\circ}$

Gaussian Smoothing: $5.0^{\circ}$

Fig. 1 EBSD scan of the copper used in this study showing an equiaxed grain structure with an average grain size of $25 \mu \mathrm{m}$

strain pulse into one of the pressure bars which then travels along it in a predictable manner until it reaches the specimen. By design, the acoustic impedance of the specimen is different to that of the pressure bars resulting in a reflected strain component, $\epsilon_{r}$, and a transmitted strain component, $\epsilon_{t}$, at the interface. These transient pulses are measured using strain gauges on the pressure bars and are recorded using a digital storage oscilloscope (DSO). So long as the pressure bars remain elastic throughout the test, the captured strain histories can be used to deduce force and displacement histories at both faces of the specimen. Equation 1 and Equation 2 can be used to work out the stress, $\sigma$ and strain rate, $\dot{\epsilon}$ :

$\sigma(t)=\frac{F_{t}(t)}{A_{0}}=\frac{A_{b} E \epsilon_{t}(t)}{A_{0}}$

$\dot{\epsilon}=\frac{V_{i}(t)-V_{t}(t)}{l_{s}}=\frac{c_{b}}{l_{s}}\left(\epsilon_{r}(t)-\epsilon_{i}(t)+\epsilon_{t}(t)\right)=\frac{2 c_{b} \epsilon_{r}(t)}{l_{s}}$

The variables $A_{b}$ and $A_{o}$ are the cross sectional area of the pressure bars and specimen and $l_{s}$ is the specimen length. In the above, $V$ is the velocity of the bar ends a given time, $t$, which are in contact with the specimen. The acoustic velocity and elastic modulus of the pressure bar material is given by $c_{b}$ and $E$. The strain, as measured by the strain guages on the pressure bars is given by $\epsilon$ with subscripts $i, r$ and $t$ denoting the incident, reflected and transmitted waves. The force magnitude in the pressure bars is given by F. For a full derivation of these equations the reader is referred to Gray [1].

Identical copper specimens were tested at a target strain rate of $3000 \mathrm{~s}^{-1}$ using both systems at temperatures of 20 ${ }^{\circ} \mathrm{C}$ and $200{ }^{\circ} \mathrm{C}$, and also at $500{ }^{\circ} \mathrm{C}$ on the new system. The material was tested at $20^{\circ} \mathrm{C}$ and $200{ }^{\circ} \mathrm{C}$ at strain rates of $10^{-2}$ and $2 \mathrm{~s}^{-1}$ using a specially built apparatus which was fitted to an Instron 5584 load frame. The specifications of the SHPB systems used in this work are given in Table 1.

\section{Imperial College London - new miniturized SHPB for hazardous materials}

This newly developed system was designed for operation inside an environmentally controlled glovebox for the evaluation of radioactive metals, but the same apparatus could be used for the evaluation of other hazardous and environmentally sensitive materials, such as biological tissues and very reactive metals which would combust under normal atmospheric conditions. The glove-box constraint meant that the apparatus needed to be miniaturized, such that an operator could reach all parts of the machine for maintenance and operation using leaded gloves. Many aspects of the experimental procedure were also automated so that interaction with the operator could be minimized. Unique mechanisms for actuating the pressure bars, transporting the specimen and for accelerating the striker bar were developed specifically for this application to enable ergonomic use. For this application is was also necessary to avoid directly instrumenting specimens for non-ambient testing as thermocouple welding was deemed unsafe and impractical inside of a glovebox environment. A method for avoiding the need to instrument specimens is presented.

A conventional gas-gun striker launcher could not be used as the sudden expulsion of compressed gas is unsafe inside an environmentally controlled glovebox. Instead the striker bar was launched using a mechanism comprising two flywheels which are rubberised around the circumference, and a series of guide rollers which constrain the striker bar to move in only one dimension, as in Fig. 2. An electrical motor accelerated the flywheels and the motion was synchronized using gears. Their velocity was modulated using a rotary encoder and a proportional integral derivative (PID) feedback system. Once the flywheels were at the 

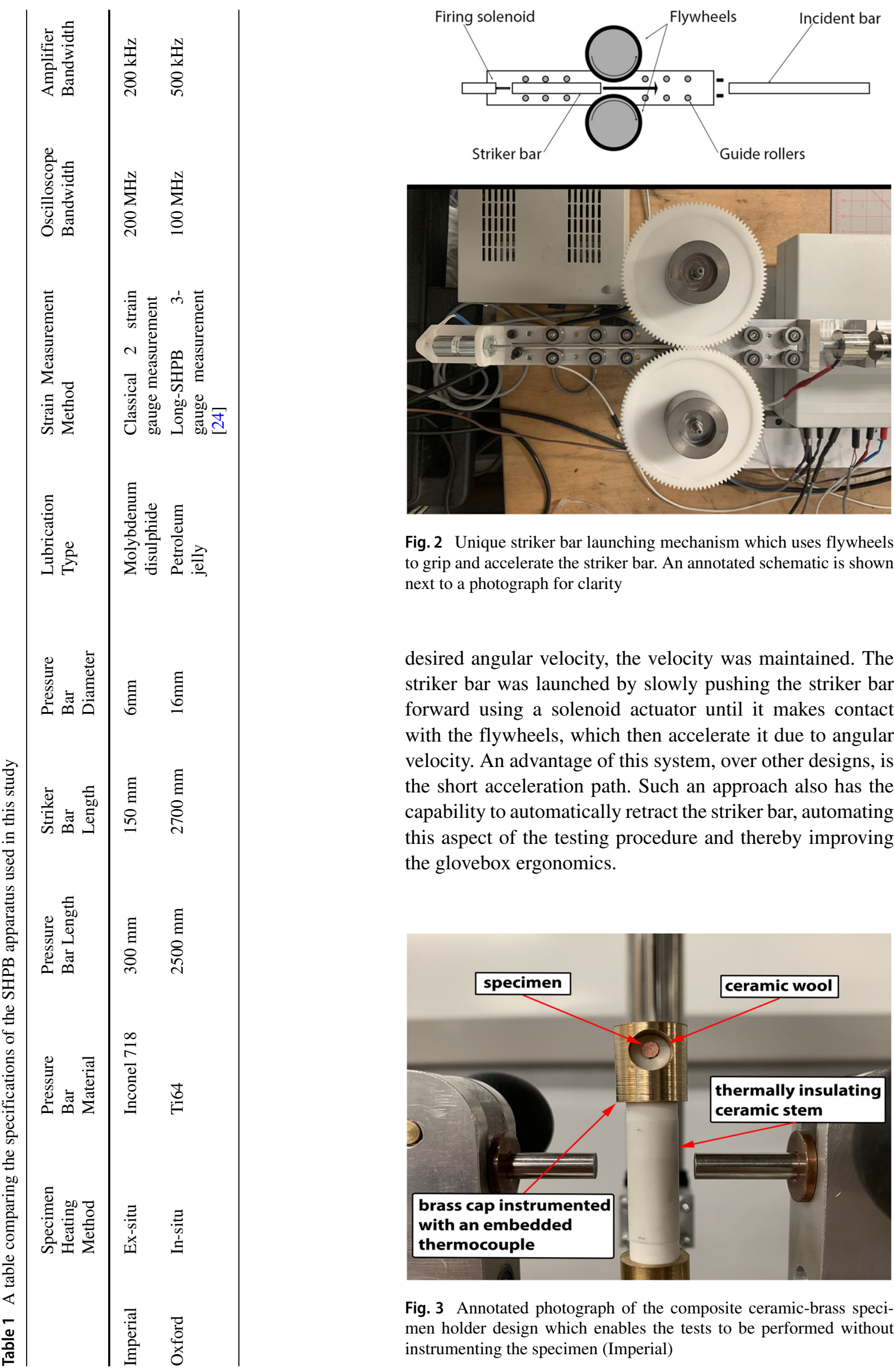

Fig. 2 Unique striker bar launching mechanism which uses flywheels to grip and accelerate the striker bar. An annotated schematic is shown next to a photograph for clarity

desired angular velocity, the velocity was maintained. The striker bar was launched by slowly pushing the striker bar forward using a solenoid actuator until it makes contact with the flywheels, which then accelerate it due to angular velocity. An advantage of this system, over other designs, is the short acceleration path. Such an approach also has the capability to automatically retract the striker bar, automating this aspect of the testing procedure and thereby improving the glovebox ergonomics.

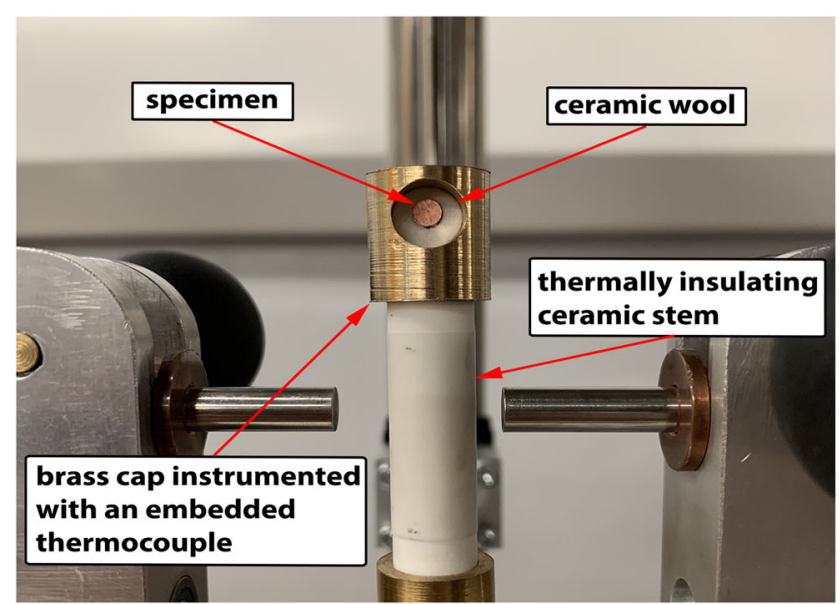

Fig. 3 Annotated photograph of the composite ceramic-brass specimen holder design which enables the tests to be performed without instrumenting the specimen (Imperial) 

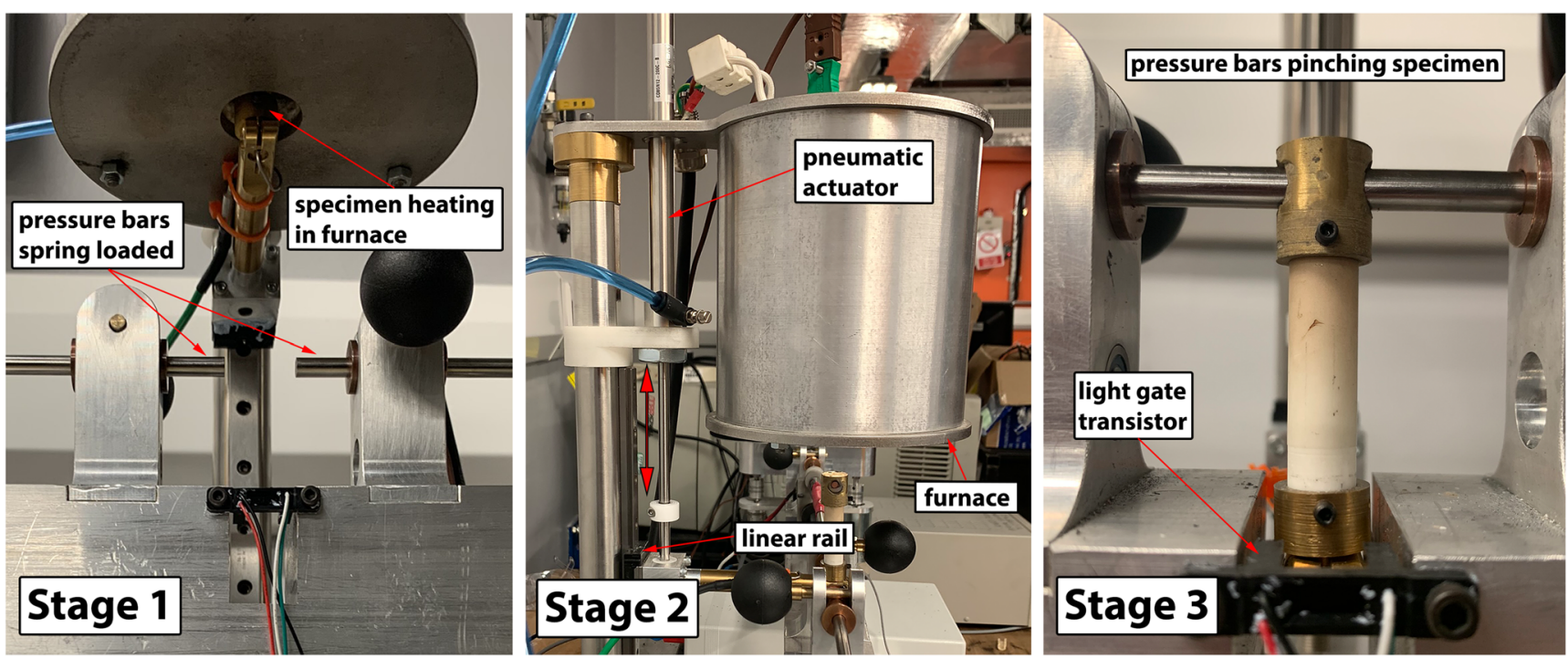

Fig. 4 Annotated photograph showing the pneumatically actuated transfer mechanism which rapidly translates the specimen between the furnace and the testing position

Specimen heating was achieved using an external furnace (ex-situ). This approach was taken as it was considered to be safer, and to maximise the service life of the instrumented pressure bars. The specimens were wrapped in a ceramic wool and placed inside a ceramic-brass composite holder as in Fig. 3. The ceramic wool is of inconsequential strength and therefore did not affect the tests. The ceramic stem of the holder acts as a thermal break thus resulting in a situation where the temperature of the brass cap is very similar to that of the specimen - this was verified experimentally. This design enables non-ambient tests to be performed without instrumenting the test specimens. Instead, only the brass cap is instrumented, the temperature of which can be used to infer the temperature of the specimen.

The holder was rapidly translated between the furnace and the test position by an assembly consisting of a linear rail and a pneumatic actuator, as in Fig. 4. A pair of needle valves at the actuator inlets were used to modulate the velocity by restricting the air supply.

The firing sequence was precisely co-ordinated by a microcontroller to ensure that the specimen-bar contact time was minimized. The pressure bars were spring loaded against a pair of electromagnets (see Fig. 5) which could be rapidly de-energized by sending a digital signal from the microcontroller. As illustrated in Fig. 4, the launch sequence proceeded as follows:

1. Specimen was heated in the furnace until the target temperature was reached.

2. Specimen was rapidly transported to the test position, passing through a light gate, sending a signal to the microcontroller.

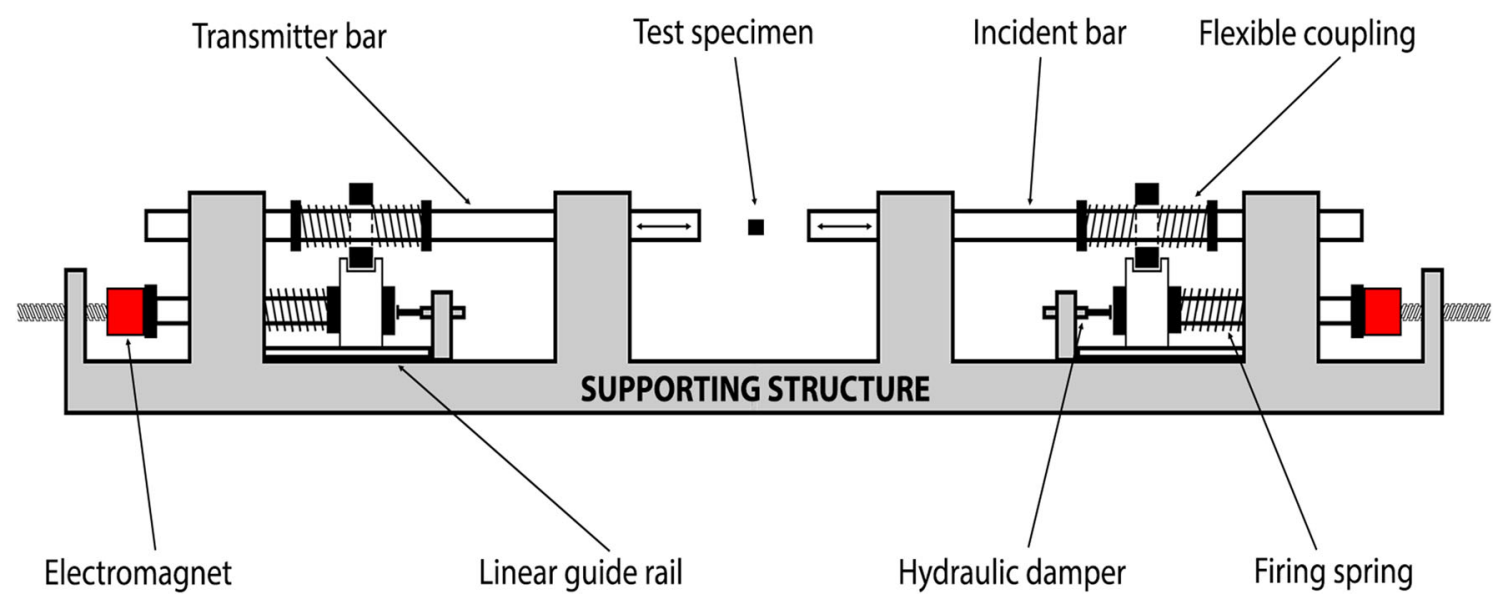

Fig. 5 Schematic showing the pressure bars spring loaded against a pair of electromagnets. When the magnets are de-energized the bars come together to pinch the test specimen immediately prior to testing, minimising specimen-bar contact time 
3. The electromagnets were de-energized and the springloaded pressure bars pinched the specimen. After a controllable delay (adjusted to $50 \mathrm{~ms}$ ), the striker bar firing solenoid was activated, accelerating the striker bar into the incident bar.

The specimen was transported from the furnace to the firing position in $<1 s$. Once in the firing position the bars would clamp the specimen and $200 \mathrm{~ms}$ later the incident stress pulse would reach the specimen. As the entire sequence is co-ordinated by a microcontroller, the contact time could be reduced further if the striker bar launch sequence was initiated prior to specimen-bar contact. The practical limit of this design is probably around 20 $\mathrm{ms}$. A longer contact time was preferred to minimise risk of damaging the equipment. Investigations into specimen cooling revealed that longer contact times were acceptable.

The use of spring-loaded electromagnetically actuated pressure bars is a new technique which is simpler to implement than pneumatic actuation and can be replicated at much lower cost. The Hopkinson bar test requires that the bars can slide freely during the test so flexible couplings were used between the bars and the actuation assembly. It is not clear from the open literature how other researchers employing ex-situ heated Hopkinson bar apparatus have dealt with this problem. Adjustable hydraulic dampers were situated in series with the firing springs, critically damping the motion of the bars to ensure the bars made smooth contact with the specimens. 'Bars-together' tests demonstrated that the bar manipulation system had no discernible effect on the transmission efficiency of the strain pulses.

\section{University of Oxford - long-SHPB with in-situ specimen heating}

This apparatus was designed to impart a very long duration loading pulse of approximately $1 \mathrm{~ms}$. A two point strain measurement technique was employed on the incident bar as the strain pulses were long enough to overlap. For a detailed description of this method the reader is referred to Zhao [24]. The apparatus has been described in another publication by DeCola [25]. This design is often referred to as a Long-SHPB, or L-SHPB. The apparatus is pictured in Fig. 6.

In some of the ambient temperature tests, specimen deformation was analysed using DIC with a Kirana5M camera running at a frame rate of $5 \cdot 10^{5} \mathrm{~s}^{-1}$ to check for the uniaxiality of straining. No attempt was made at correcting for the thermal gradient introduced into the pressure bars as the disturbance is small at the temperatures of interest.

Specimen heating was achieved using a resistance heated furnace which was placed over the pressure bars, and heated both the pressure bars and specimen. The specimens were directly instrumented with welded thermocouples to determine the temperature.

\section{Results and discussion}

\section{Quasi-Static, intermediate and ambient Hopkinson bar results}

Firstly, the material was evaluated at quasi-static and intermediate rates of strain to establish a baseline material response, against which the SHPB data could be validated. Compression specimens for non-dynamic testing would typically be of a different geometry and of much greater size [26], but in this study, the same specimen geometries were used for consistency. A specially built apparatus was used as in Fig. 7(a). Specimen displacement was measured using a triad of linear variable differential transformers (LVDT). Using 3 LVDT's enabled the quantification of any imbalance, which was found to be negligible. Tungsten carbide platens were used as the very high elastic

Fig. 6 Annotated photograph of the in-situ heated Hopkinson bar system showing how the furnace is placed over the pressure bars (Oxford)

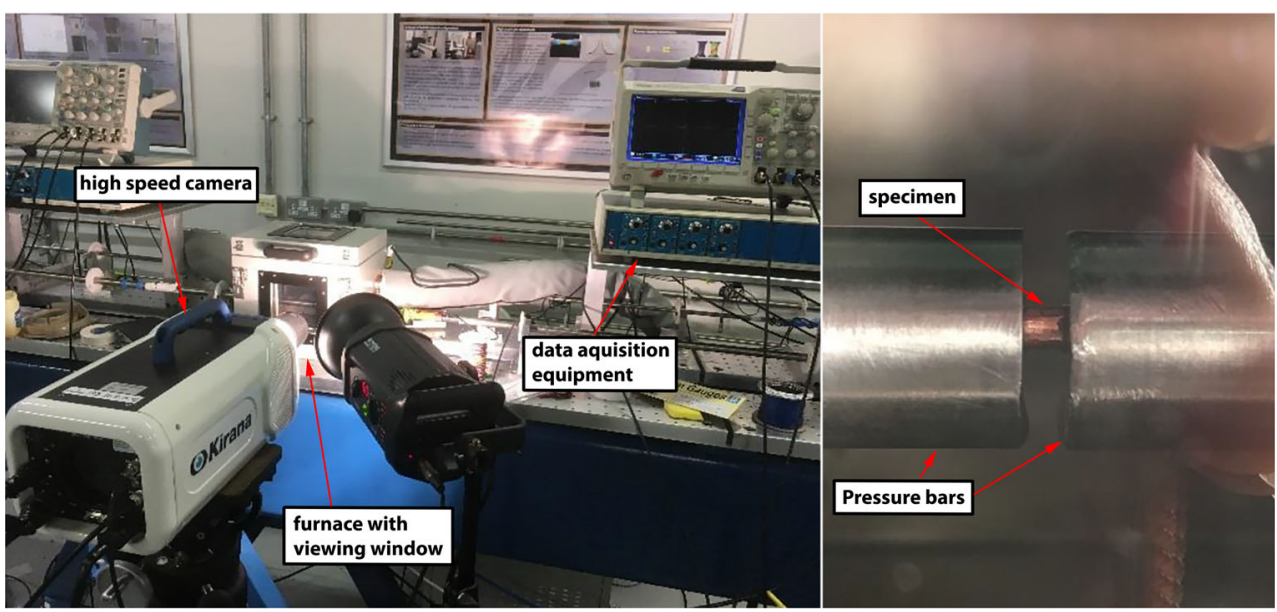




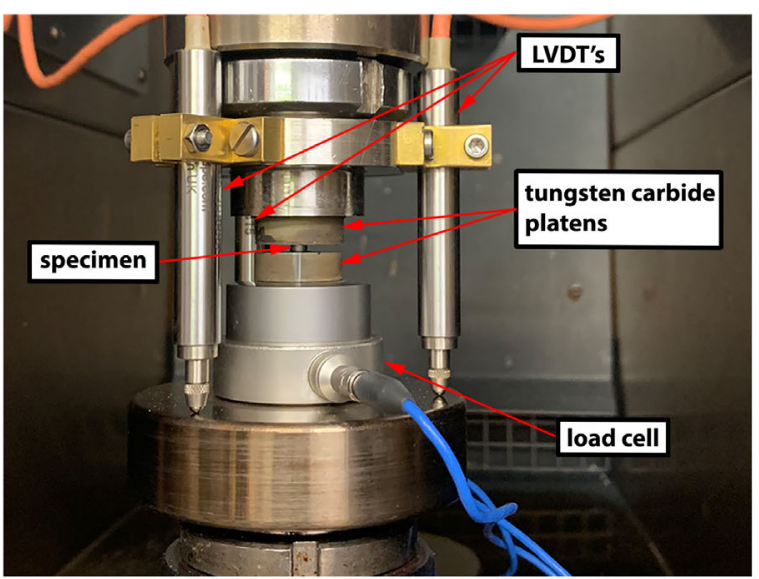

(a)

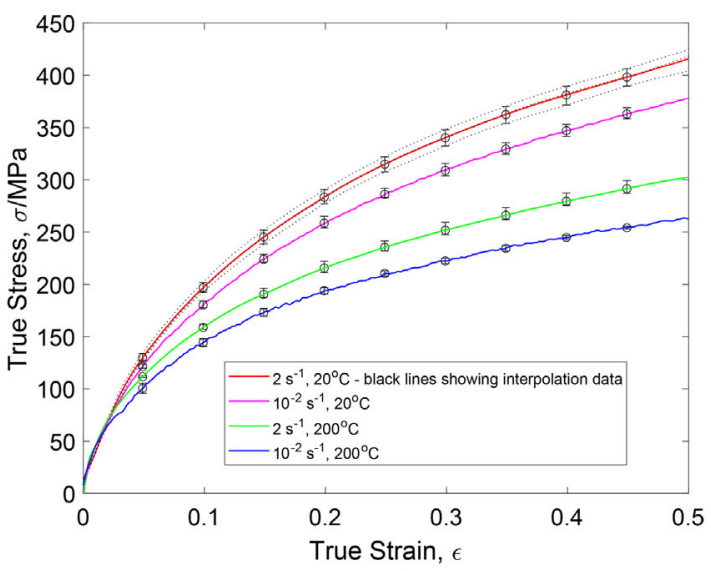

(b)

Fig. 7 (a) Shows a purpose built compression rig which has been designed specifically for testing of small compression specimens. 3 LVDT's measure the displacement, (b) a plot showing the compressional response of the copper at $10^{-2}$ and $2 s^{-1}$ and at 20 and $200{ }^{\circ} \mathrm{C}$. The data was collected using the purpose built rig

modulus $(600 \mathrm{GPa})$ relative to the specimen material (117 $\mathrm{GPa}$ ), minimizes the elastic indentation of the platens, sometimes called 'punching' [11], which could constrain radial expansion of the specimen. The entire apparatus was designed to be temperature resistant up to $200{ }^{\circ} \mathrm{C}$ and to be operable inside of an environmental chamber.

The quasi-static and intermediate rate data are displayed in Fig. 7(b). Each test was performed in triplicate and a line of best fit was numerically interpolated through the data sets for each rate and temperature combination, forming a smooth line with no obvious transition point from elastic to plastic flow behaviour. The flow stress increased with the strain rate and decreased with increasing temperature.

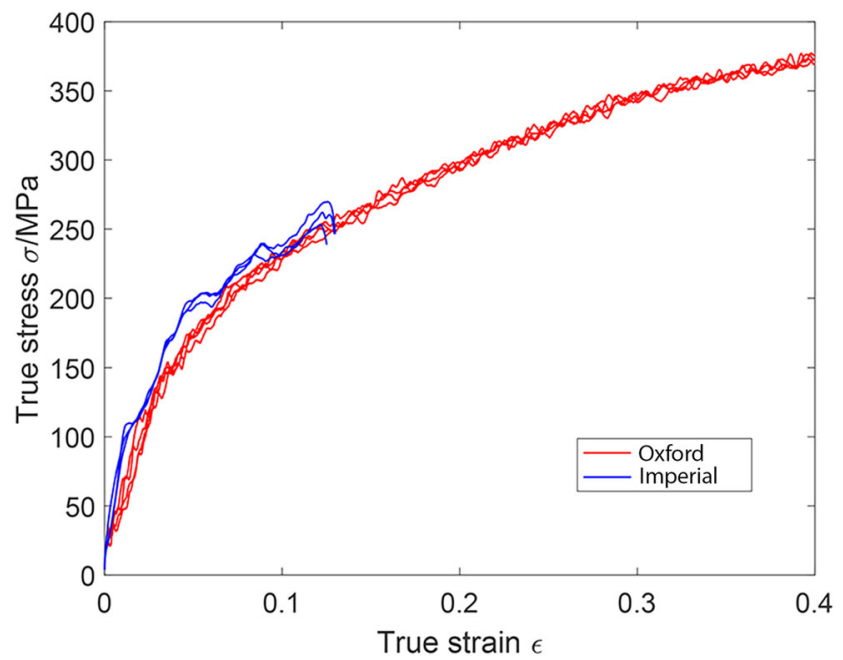

Fig. 8 Comparison of room temperature Hopkinson bar data attained by both laboratories. The strain rate varied from 1900-2600 $\mathrm{s}^{-1}$ during the Imperial tests and was more consistently $2500 \mathrm{~s}^{-1}$ for the Oxford tests
Hopkinson bar results attained at room temperature were remarkably consistent at both laboratories despite the lack of agreed standards. A comparison of the room temperature data for both laboratories is made in Fig. 8. The solid blue line in Fig. 8 is from Imperial which is the new miniaturised SHPB. The solid red line is from Oxford.

Both laboratories regularly calibrate the pressure bars and data acquisition train. At Imperial, the calibration is performed by mounting the pressure bars into a load frame with a calibrated load cell, and then subjecting the pressure bars to a tensile force. The data from the strain gauges on the pressure bars, which is run through the same amplifier and DSO used in the experiments, is plotted against the measured force to determine the pressure bar sensitivity directly. The calibrated load cells used are accurate to within $0.25 \%$ of the measured load. The uncertainty in the force measurement at Imperial was $<0.5 \%$. Due to the length of the pressure bars on the Oxford system, a different calibration procedure was employed, with an estimated uncertainty of $<2 \%$. The uncertainty in the specimen loading area was $<1 \%$ which, through propagation of uncertainty, results in a maximum interlaboratory uncertainty in the stress calculation of $4 \%$.

For a given striker bar impact velocity, the amount of strain that is imparted into the specimen is directly proportional to the duration of the loading pulse, which in turn is directly proportional to the length of the striker bar, $l_{\text {striker }}$. The duration of the loading pulse, $t_{\text {pulse }}$, is given by:

$t_{\text {pulse }}=\frac{2 l_{\text {striker }}}{c_{b}}$

The length of the striker bar used by Oxford was an order of magnitude longer than at Imperial, which resulted in a much larger total strain being imparted, producing a 


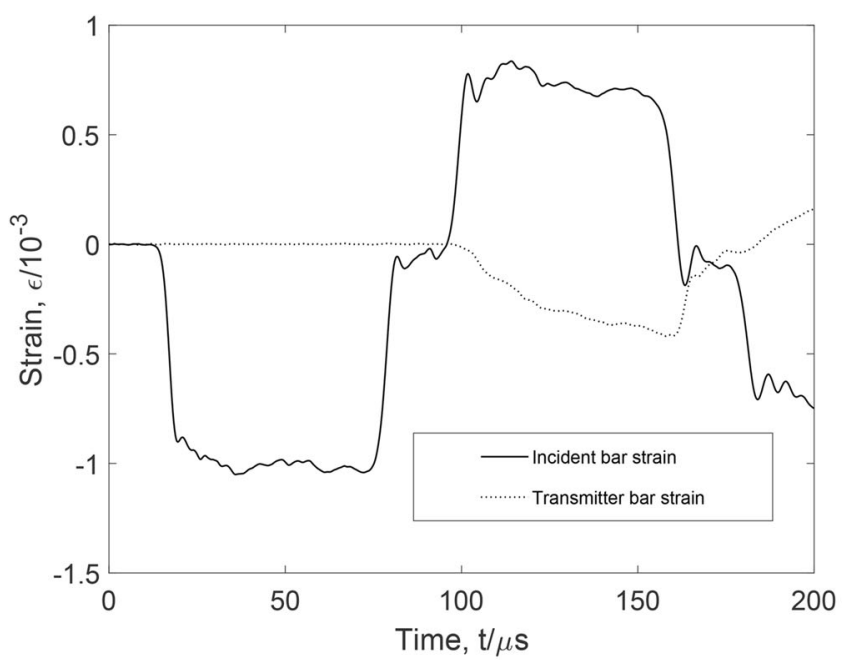

(a)

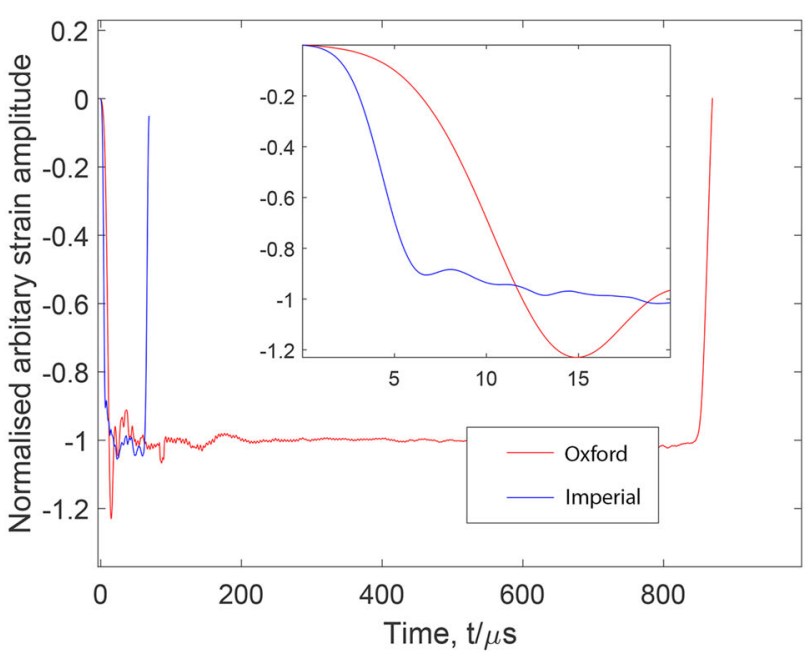

(c)

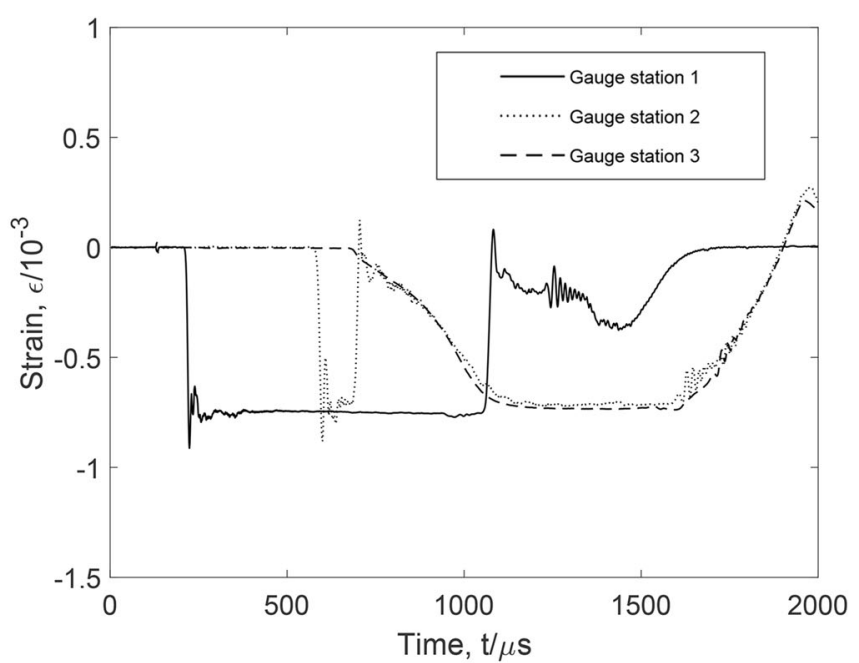

(b)

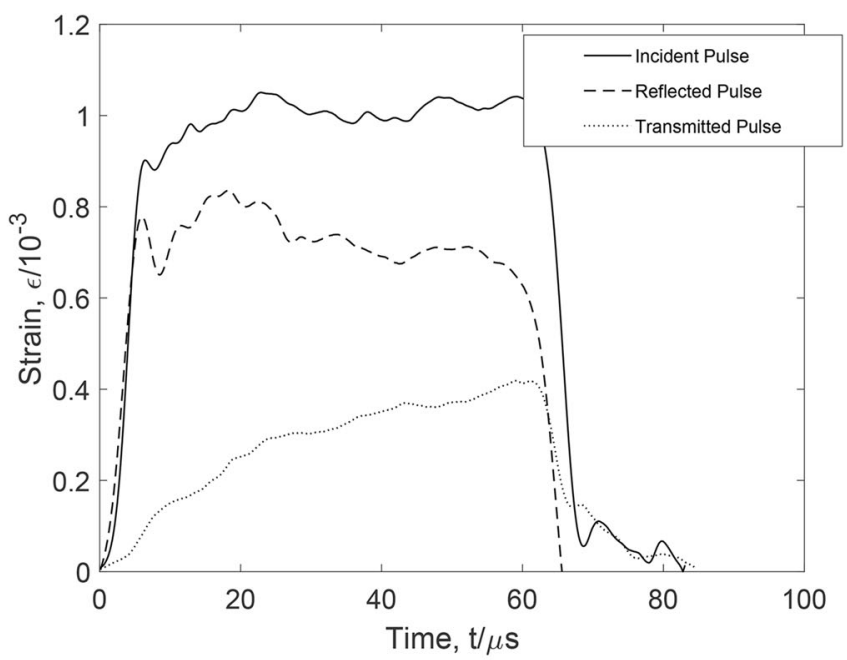

(d)

Fig. 9 (a) A plot of the raw strain pulses attained at Imperial, (b) a plot of the raw strain pulses attained at Oxford, (c) a comparison of the incident pulses at both Imperial and Oxford, with a zoomed in view showing the that the pulse from Oxford has a much longer rise time as a result of more severe dispersion, (d) isolated and aligned strain pulses from Imperial

continuous adiabatic curve that reached well beyond 0.5 true strain. It was estimated that the specimen temperature increased by approximately $50^{\circ} \mathrm{C}$ at a true strain of 0.5 . The striker bar length used by Imperial is fixed by design and cannot be easily changed. As can be seen from Fig. 9(a), if the striker bar was any longer, there would be overlap of the strain pulses which would require an extra strain gauge station.

An example set of strain pulses from Imperial and Oxford are given in Fig. 9(a) and Fig. 9(b) respectively. Identifying the start of the strain pulses can be easily done through visual inspection or using a simple thresholding algorithm, however a source of uncertainty in Hopkinson bar testing is in the alignment of the isolated strain pulses as seen in Fig. 9(d), where they are not all the same length. Pulse alignment techniques such as cross-correlation or autocorrelation can be used but it is typical to align the pulses according to their starting position [6].

Both laboratories acquired the data using different acquisition equipment and processed the data using different algorithms. This was a further challenge to the robustness of the Hopkinson bar test. Due to the bar designs being different, with Oxford utilizing a 3-gauge strain measurement and Imperial using a 2-gauge strain measurement, the data processing algorithms were not interchangeable.

The initial portion of the stress-strain curve from Imperial is steeper. It is considered that this is predominantly due to differing frictional conditions, with the friction at Imperial being more severe. Another explanation for this is the shorter rise time of the loading pulse, which is 
approximately a factor of 3 quicker. A higher magnification view of the beginning of the loading pulse is given in Fig. 9(c). The shorter, thinner bars result in less severe dispersion. Additionally, differences in the pulse alignment procedures adopted have the capacity to affect the calculated flow stress. Note that if the stress-strain curves are shifted slightly in Fig. 8 then the curves would correlate more closely.

The oscillations that can be seen on the stress-strain curve in Fig. 8 for the Imperial case are attributable to nonperfect alignment between the striker bar and the incident bar which caused oscillations in the loading wave as can be seen in Fig. 9(d). This imperfect offloading of the strain pulse is a form of pulse shaping as it causes the shape of the loading pulse to deviate from a square shape. Pulse shaping is typically done on purpose and is used to tailor the strain rate through the test but in this case, it was not intended. When using a gas gun to fire the striker bar one can ensure alignment between the striker bar and the incident bar by sliding the incident bar down the barrel of the gas gun [11]. This was not possible as the striker bar was launched by a pair of flywheels. A future design iteration of the apparatus will address this problem.

Frictional conditions are influenced by the different lubricants used, the pressure bar material and the surface finish of the pressure bars. A study on the effect of lubricant type demonstrates that discrepancies greater than those seen here can arise from this alone [5]. It is possible to effectively correct for the frictional effects by first determining the coefficient of friction using ring compression tests [27] and then inputting this value into an equation of the form proposed by Gorham [28], however, the effect of friction is generally ignored.

\section{Non-ambient Hopkinson bar results}

To ensure a valid comparison between the non-ambient SHPB testing methods, experiments were performed to determine the rate of specimen cooling during transport and bar contact in the ex-situ case at Imperial. Dummy specimens were instrumented with $0.2 \mathrm{~mm}$ K-type thermocouples which were resistance welded to their surface. The specimens were heated and then allowed to cool under two conditions:

1. In air.

2. In contact with pressure bars.

In air, the cooling was found to proceed at a maximum rate of $<2{ }^{\circ} \mathrm{C} \mathrm{s}^{-1}$ as the specimen was transported in a special holder which was designed to minimise cooling. The furnace to bar transportation time was less than $1 s$ so the cooling during transport was taken to be negligible. However, the cooling after specimen-bar contact was found to be extremely rapid, particularly at higher temperatures. The instrumented specimens were brought into contact with the pressure bars at various temperatures and an Omega OMB-3001 thermocouple reader was used to log the temperature decay at a frequency of $200 \mathrm{~Hz}$. Two repeats were performed at each temperature. The results are plotted in Fig. 10(a).

As the specimen-bar contact time was $200 \mathrm{~ms}$, only the initial cooling rate of the specimens was of interest. The temperature decay was approximately linear across the first $0.5 \mathrm{~s}$. The initial specimen cooling rate, $\dot{T}$, was plotted against the initial specimen temperature, $T_{\text {initial }}$, as in Fig. 10(b), and a line was fitted to the data using a linear least squares approach. The equation of this line is therefore the relation of the cooling rate with the initial specimen temperature, which is given by Equation 4.

$\dot{T}=0.379 T_{\text {initial }}-10.62$

Equation 4 was used to calculate the required initial specimen temperature to achieve the target test temperature. Given that the specimen-bar contact time contact time was repeatably $200 \mathrm{~ms}$, the specimens were required to be overheated by $15{ }^{\circ} \mathrm{C}$ for the $200{ }^{\circ} \mathrm{C}$ tests and by $40{ }^{\circ} \mathrm{C}$ for the $500{ }^{\circ} \mathrm{C}$ tests. Modelling of the conductive cooling process was done using ABAQUS. The specimens were wrapped in an insulating ceramic wool, so the circumference of the specimens was taken to be adiabatic. Convective and radiative cooling could be neglected as the conductive cooling mechanism was overwhelmingly dominant during specimen-bar contact.

The results from the simulation were in very good agreement with the experimental data, see Fig. 10(c). Textbook values for the thermal conductivity, specific heat capacity and density of the pressure bars and specimen were used. The thermal properties of the materials were taken to be constant with respect to temperature as variations in the values are small across the temperature range under consideration. A contact parameter denoted by $h_{t, c}$, which is known as contact conductance generally, but in ABAQUS is called 'gap conductance', was used to describe the quality of the thermal contact between the specimen and pressure bars. The contact conductance is a means of describing imperfect thermal contact between surfaces by accounting for the fact that at low contact pressures, surface irregularities ensure that contact is made only at a few discrete points [29]. The rate of heat transfer from the specimen is very strongly related to the contact conductance between the specimen and the pressure bars, with specimen parallelism being the most important factor.

The surface roughness of the contacting surfaces, the contact pressure and the elemental composition of the ambient atmosphere all affect the contact conductance magnitude. Typical values fall in the range of $2000<$ 


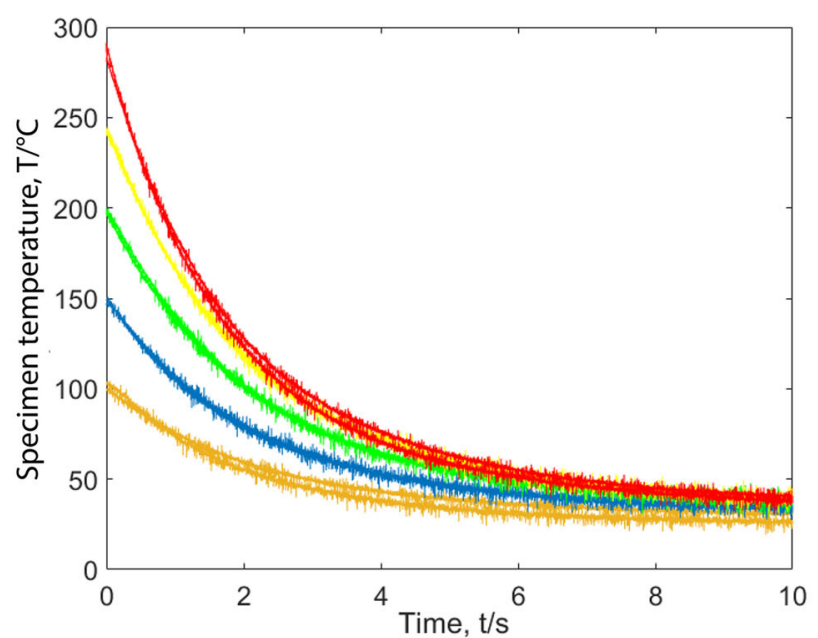

(a)

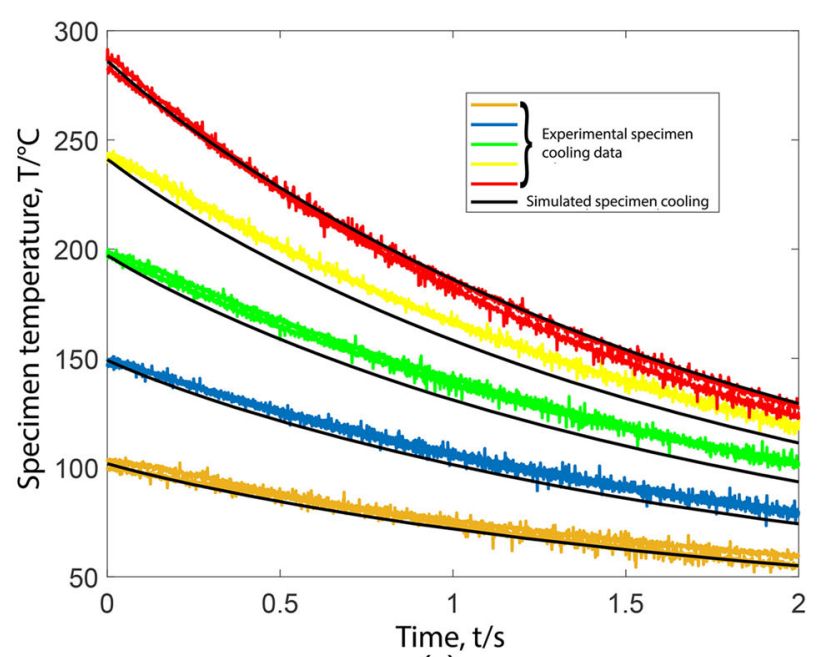

(c)

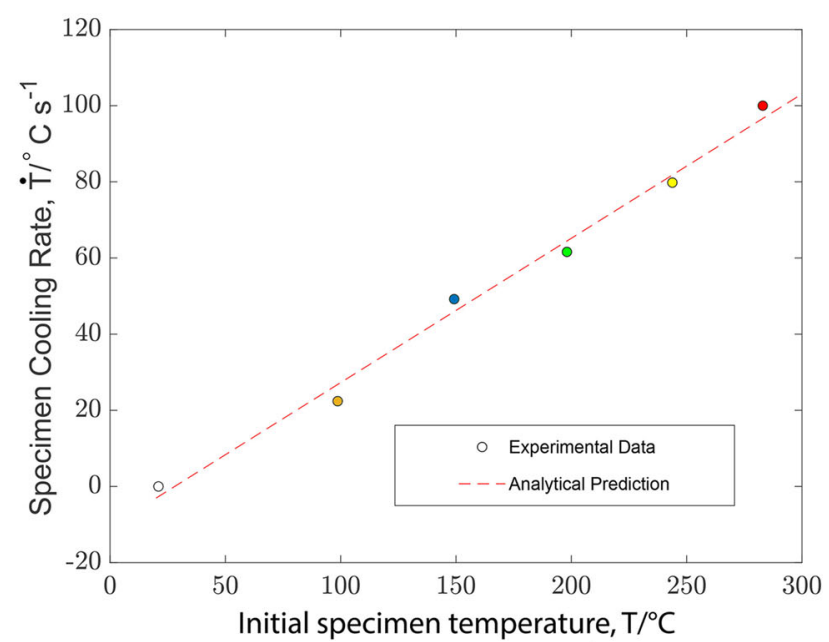

(b)

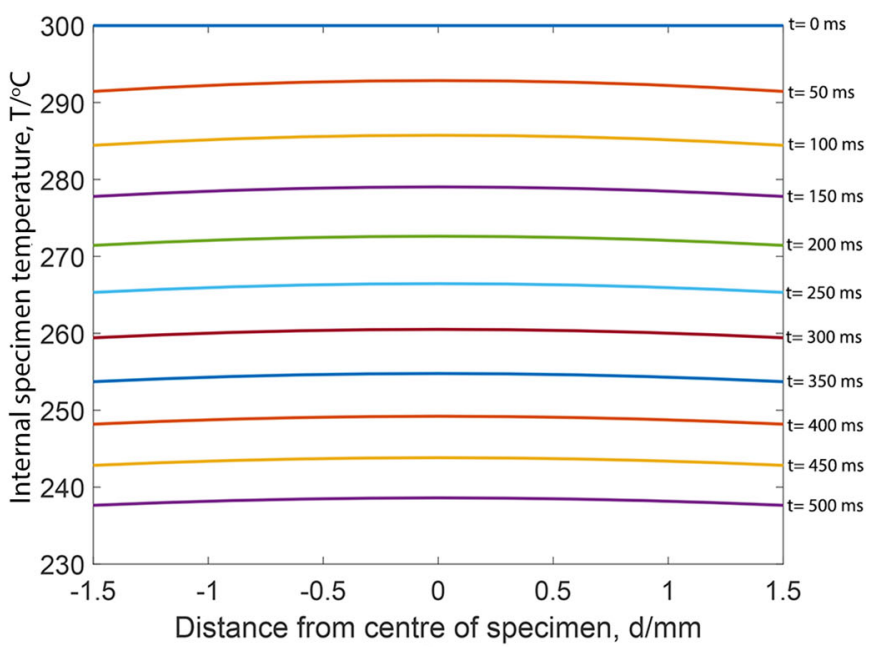

(d)

Fig. 10 (a) A plot showing experimental measurements of specimen cooling upon contact with the pressure bars. Each colour represents a different starting temperature, (b) a plot of the specimen cooling rate vs the initial specimen temperature. The initial cooling rate is an average across the first $0.5 \mathrm{~s}$. Coloured data points correspond with the previous figure, (c) a comparison of experimental specimen cooling data with ABAQUS finite element simulations, showing very good agreement, (d) a plot of the spatial temperature distribution inside the specimen towards the pressure bars with respect to time after bar contact, showing that the temperature inside the specimen is homogeneous

$h_{t, c}<200000 \mathrm{Wm}^{-2} \mathrm{~K}^{-1}[30]$, however experiments to attain these values are typically performed with contact pressures of at least $1 \mathrm{MPa}$ and surface roughness values of $<10 \mu \mathrm{m}$. A value of $h_{t, c}=3000 \mathrm{Wm}^{-2} \mathrm{~K}^{-1}$ was found to match the experimental cooling data. It is important to experimentally verify specimen cooling for each test case as an assumption of 'perfect thermal contact' when modelling is not realistic and will result in a severe over-estimation of the cooling rate.

The ABAQUS simulations demonstrated that the temperature distribution within the specimen was homogeneous to within $5{ }^{\circ} \mathrm{C}$ even during rapid cooling. The internal specimen temperature distribution with respect to time is plotted in Fig. 10(d). Berkovic [31] draws a similar conclusion when performing Hopkinson bar testing on specimens at cryogenic temperatures. The specimen temperature homogeneity is due to the fast heat transfer within the specimen caused by a combination of high thermal conductivity and a small volume, coupled with a much less conductive set of pressure bars conducting the heat away. Copper has a conductivity of $401 \mathrm{~W} / \mathrm{mK}$ whereas the Inconel bars have a conductivity of $11.2 \mathrm{~W} / \mathrm{mK}$. In the field of heat transfer this situation is known as 'lumped capacitance' [32].

The cooling rate, $\dot{T}$, of a specimen contacting the pressure bars is more strongly related to the volumetric heat capacity of the specimen material than it is to the thermal conductivity. For example, iron and copper were 
found to cool at a similar rate. Temperature homogeneity is strongly influenced by the thermal diffusivity of the specimen material. In the case of pure titanium, simulations reveal that the temperature would vary by about $30{ }^{\circ} \mathrm{C}$ across an identically sized specimen when cooling from $300{ }^{\circ} \mathrm{C}$. Larger specimens would obviously suffer worse temperature homogeneity issues which makes the contact time more critical.

At higher temperatures, the variance in the stress-strain curves produced by each laboratory is slightly larger, see Fig. 11. Discrepancies might be partly attributable to temperature uncertainty. The test temperature at Imperial was estimated to be accurate to within $\pm 15{ }^{\circ} \mathrm{C}$. In the tests performed by Oxford, the specimens were directly instrumented for the entire test bringing the uncertainty down to an estimated $\pm 5^{\circ} \mathrm{C}$.

The steeper rise in the initial portion of the curve in the results attained at Imperial was still present. This is again likely to have been related to the differences in the the frictional conditions, pulse alignment and dispersion of the wave being more severe in the larger diameter pressure bars, coupled by further distortion of the wave caused by the thermal gradient. At $200^{\circ} \mathrm{C}$, the elastic modulus of the Ti64 pressure bars was estimated to have decreased by $5 \%$ [33].

To quantify the extent of the differences in the flow stress attained at either laboratory, the average absolute relative error, AARE, was chosen as an appropriate statistical measure, given by Equation 5 .

$A A R E=\frac{1}{N} \sum_{i=1}^{N}\left|\frac{\sigma_{2}-\sigma_{1}}{\sigma_{1}}\right|$

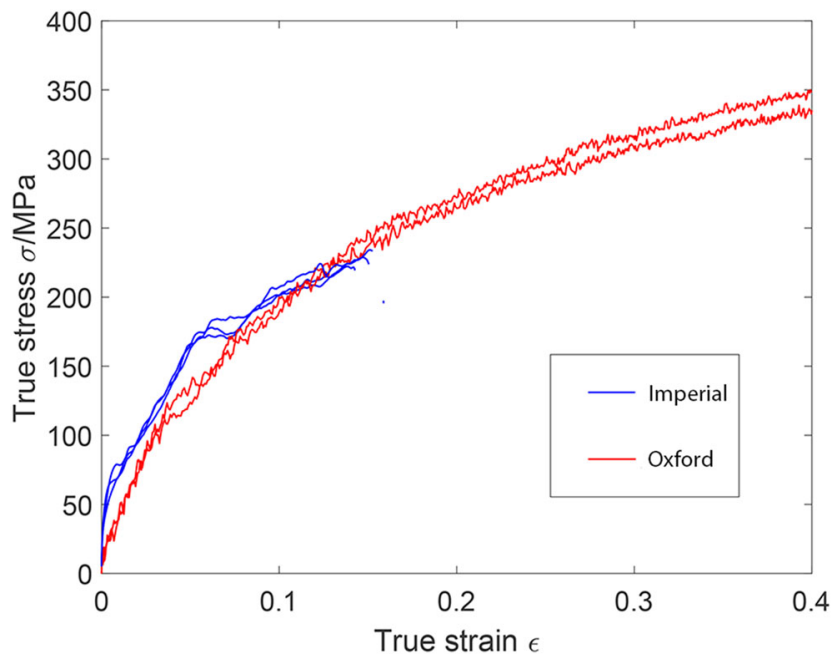

Fig. 11 Comparison of Hopkinson bar results at $200^{\circ} \mathrm{C}$

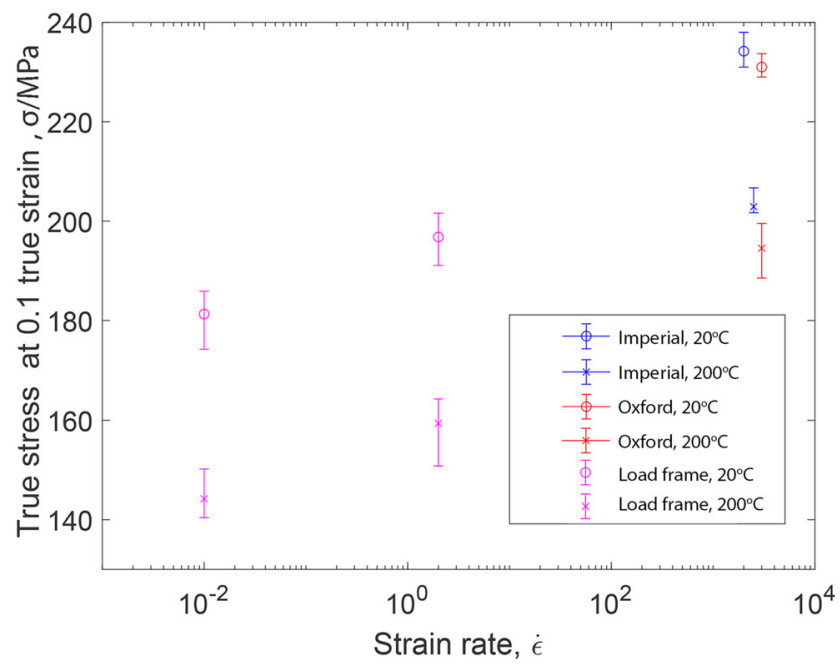

Fig. 12 The true stress at a true strain of 0.1 is plotted against the strain rate. The copper shows the quasi log-linear behaviour that is expected

The quasi-static and intermediate rate data fits well with the data attained using both Hopkinson bar procedures. As can be seen in Fig. 12, the flow stress at 0.1 strain follows the quasi log-linear relation between flow stress and strain rate that is to be expected for an annealed FCC metal. The discrepancy in the flow stress for the Hopkinson bar tests observed at 0.1 strain is less than $5 \%$ at both $20^{\circ} \mathrm{C}$ and 200 ${ }^{\circ} \mathrm{C}$.

The AARE was found to be $12.76 \%$ for the room temperature tests and $12.46 \%$ for the tests conducted at 200 ${ }^{\circ} \mathrm{C}$. As has been noted, the initial gradient in the flow stress for both comparisons is quite dissimilar before it then begins to converge. If the AARE is taken from 0.05 strain onwards, the AARE decreases to $2.9 \%$ and $6.55 \%$, respectively.

To demonstrate the capability of the new semi-automated Hopkinson bar apparatus, it has also been employed to evaluate the same material at a temperature of $500{ }^{\circ} \mathrm{C}$ and the stress-strain results are shown compared with Hopkinson bar data for $200{ }^{\circ} \mathrm{C}$ and $20{ }^{\circ} \mathrm{C}$ in Fig. 13(a). It is clear from Fig. 13(a) that the observed oscillations in the flow stress are systematic as they are present at all temperatures and seem to occur at the same fraction of total plastic strain. As previously mentioned, it is thought that these are caused by the unusual shape of the loading pulse which causes some unusual variation in the strain rate throughout the test. The flow stress at 0.1 strain is plotted against the temperature in Fig. 13(b). The thermal softening trend is in broadly good agreement with the work of Nemat-Nasser [34], who has performed SHPB testing on annealed copper. The copper displays an approximately linear relationship between the flow stress and the temperature at the strain rate tested. 


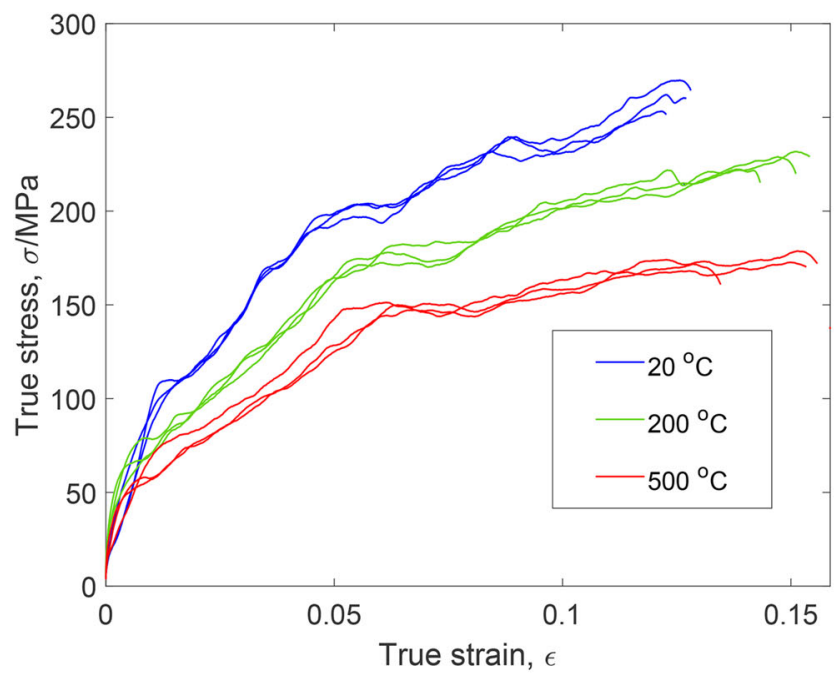

(a)

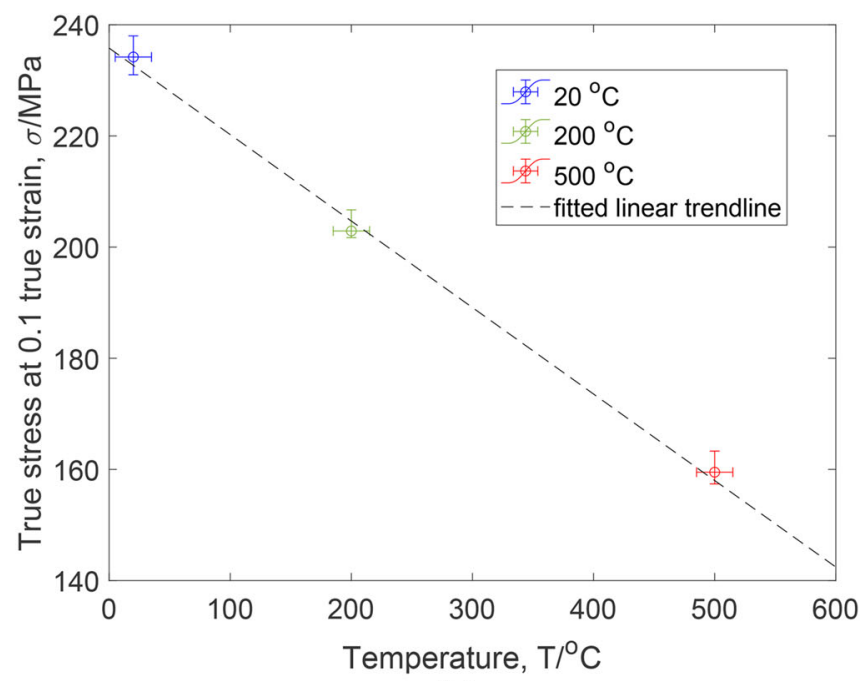

(b)

Fig. 13 (a) a true stress vs true strain plot of the copper at temperatures of 20,200 and $500{ }^{\circ} \mathrm{C} .500{ }^{\circ} \mathrm{C}$ is at the limit of what the new aparatus can achieve (b) the flow stress of the copper at a true strain of 0.1 , plotted against the testing temperature. The trend line was numerically fitted and is meant to guide the eye

\section{Conclusions}

The following conclusions can be drawn from the research:

1. A novel miniaturised SHPB has been developed and is proven effective at performing non-ambient tests where environmental isolation and handling are important considerations for safety.

2. A novel striker bar launching mechanism has been presented and demonstrated to be effective at launching the striker bar without the use of compressed gasses, which are deemed unsafe inside of the environmentally controlled glovebox environment.

3. A simple electromagnetic pressure bar manipulation system has been presented which can facilitate ex-situ Hopkinson bar testing with minimal pressure bar-specimen contact times (200 ms).

4. A procedure which can account for specimen cooling during non-ambient Hopkinson bar testing using the exsitu method has been presented and has been shown to be effective by comparing the results with some in-situ heated tests, where the temperature of the test specimen is more certain.

5. The inter-laboratory variability in the flow stress which could be attributed to the uncertainty in measurement of flow stress between Imperial and Oxford was 4\%. The differences in the results were at times higher than this, suggesting that the differences were attributable to other phenomena which are known to introduce errors into the test, predominantly friction, loading pulse shape and pulse alignment techniques.

6. Strain rate effects for the material are consistent with the quasi-static and intermediate rate tests.

It is considered that the new semi-automated Hopkinson bar apparatus that has been developed, which incorporates novel features designed to enable the testing of hazardous materials, is a valuable addition to high rate materials stress-strain evaluation. This technique has been shown to provide reliable data for stress-strain behaviour at a strain rate of approximately $3000 s^{-1}$ and at temperatures up to $500{ }^{\circ} \mathrm{C}$.

Acknowledgments Dr Robert Quinn would like to thank Dr Roger White at Natural Impacts Limited for the thoughtful discussion regarding all aspects of SHPB testing during his $\mathrm{PhD}$ and for the assistance of Natural Impacts in designing and manufacturing the new apparatus. The financial and technical support from AWE Plc is also very much appreciated.

Author Contributions All authors contributed to the study conception and design. Material preparation, data collection and analysis were performed by Robert Quinn and Longhui Zhang. The first draft of the manuscript was written by Robert Quinn and all authors commented on previous versions of the manuscript. All authors read and approved the final manuscript.

Compliance with Ethical Standards There is no conflict of interest. Robert Quinn received a grant from AWE Plc to carry out this research program. [Grant number MESMP65794] 
Open Access This article is licensed under a Creative Commons Attribution 4.0 International License, which permits use, sharing, adaptation, distribution and reproduction in any medium or format, as long as you give appropriate credit to the original author(s) and the source, provide a link to the Creative Commons licence, and indicate if changes were made. The images or other third party material in this article are included in the article's Creative Commons licence, unless indicated otherwise in a credit line to the material. If material is not included in the article's Creative Commons licence and your intended use is not permitted by statutory regulation or exceeds the permitted use, you will need to obtain permission directly from the copyright holder. To view a copy of this licence, visit http:// creativecommonshorg/licenses/by/4.0/.

\section{References}

1. Gray III GT (2000) Classic Split-Hopkinson pressure bar testing. In: ASM Handbook, vol 8, pp 462-476

2. Jordan JL, Siviour CR, Sunny G, Bramlette C, Spowart JE (2013) Strain rate-dependant mechanical properties of OFHC copper. Journal of Materials Science 48(20):7134-7141

3. Gorham DA (1989) Specimen inertia in high strain-rate compression. Journal of Physics D: Applied Physics 22(12):1888-1893

4. Lu F, Lin Y, Wang X, Lu L, Chen R (2015) A theoretical analysis about the influence of interfacial friction in SHPB tests. International Journal of Impact Engineering 79:95-101

5. Zhong WZ, Rusinek A, Jankowiak T, Abed F, Bernier R, Sutter G (2015) Influence of interfacial friction and specimen configuration in Split Hopkinson Pressure Bar system, vol 90

6. Lifshitz JM, Leber H (1994) Data processing in the split Hopkinson pressure bar tests. International Journal of Impact Engineering 15(6):723-733

7. Siviour CR, Walley SM (2018) Inertial and Frictional Effects in Dynamic Compression Testing. In: The Kolsky-Hopkinson Bar Machine Springer International Publishing, Cham, pp 205-247

8. Bragov AM, Lomunov AK, Lamzin DA, Konstantinov AY (2019) Dispersion correction in split-Hopkinson pressure bar: theoretical and experimental analysis Continuum Mechanics and Thermodynamics

9. Tyas A, Ozdemir Z (2014) On backward dispersion correction of Hopkinson pressure bar signals. Philosophical Transactions of the Royal Society A: Mathematical, Physical and Engineering Sciences 372(2023):20130291

10. Kariem MA, Santiago RC, Govender R, Shu DW, Ruan D, Nurick G, Alves M, Lu G, Langdon GS (2019) Round-robin test of split Hopkinson pressure bar. International Journal of Impact engineering 126(2018):62-75

11. Lea L, Jardine A (2018) Measuring structural evolution in the dynamic plasticity of FCC metals $\mathrm{PhD}$ thesis University of Cambridge

12. Chiddister JL, Malvern LE (1963) Compression-impact testing of aluminum at elevated temperatures. Exp Mech 3(4):81-90

13. Krafft JM, Sullivan AM, Tipper CF (1954) The effect of static and dynamic loading and temperature on the yield stress of iron and mild steel in compression. In: Proceedings of the Royal Society of London. Series A. Mathematical and Physical Sciences, vol 221, pp 114-127

14. Samanta SK (1971) Dynamic deformation of aluminium and copper at elevated temperatures. Journal of the Mechanics and Physics of Solids 19(3):117-135

15. collab=C. E. Frantz, P. S. Folansbee, and W. J. Wright. New experimental techniques with the split hopklnson pressure bar.
Technical report, Los Alamos National Lab (1984) NM (USA) Report number: LA-UR-83-3422

16. Davoodi B, Gavrus A, Ragneau E (2005) An experimental and numerical analysis of the heat transfer problem in SHPB at elevated temperatures. Meas Sci Technol 16(10):2101-2108

17. Kuokkala V, Apostol M, Hokka M (2010) High and low temperature techniques in Hopkinson Split Bar testing. In: IMPLAST

18. Kajberg J, Sundin KG (2013) Material characterisation using high-temperature Split Hopkinson pressure bar. Journal of Materials Processing Technology 213(4):522-531

19. Sizek HW, Gray GT (1993) Deformation of polycrystalline Ni3Al at high strain rates and elevated temperatures. Acta Metallurgica et Materialia 41(6):1855-1860

20. Walley SM (2019) The effect of temperature gradients on elastic wave propagation in split Hopkinson pressure bars. Journal of Dynamic Behavior of Materials. https://doi.org/10.1007/s40870-020-00245-9

21. Bacon C, Carlsson J, Lataillade JL (1991) Evaluation of force and particle velocity at the heated end of a rod subjected to impact loading, vol 01

22. Lee W, Xiea G, Lin C (1998) The strain rate and temperature dependence of the dynamic impact response of tungsten composite. Materials Science and Engineering:A 257(2):256-267

23. Lea LJ, Jardine AP (2018) Characterisation of high rate plasticity in the uniaxial deformation of high purity copper at elevated temperatures. Int J Plast 102:41-52

24. Zhao H, Gary G (1997) A new method for the separation of waves Application to the SHPB technique for an unlimited duration of measurement. Journal of the Mechanics and Physics of Solids 45(7):1185-1202

25. De Cola F, Pellegrino A, Glößner C., Penumadu D, Petrinic N (2018) Effect of Particle Morphology, Compaction, and Confinement on the High Strain Rate Behavior of Sand. Experimental Mechanics 58(2):223-242

26. ASTM E9-19 (2019) Standard test methods of compression testing of metallic materials at room temperature

27. Sofuoglu H, Rasty J (1999) On the measurement of friction coefficient utilizing the ring compression test. Tribology International 32(6):327-335

28. Gorham DA, Pope PH, Field JE (1992) An improved method for compressive stress-strain measurements at very high strain rates. In: Proceedings of the Royal Society of London Series A: Mathematical and Physical Sciences, vol 438, pp 153-170

29. Wahid MS, Madhusudana CV (2000) Gap conductance in contact heat transfer. International Journal of Heat and Mass Transfer 43(24):4483-4487

30. Cengal Y (2010) Introduction to thermodynamics and heat transfer Mcgraw-hill Education USA

31. Berkovic L, Chabotier A, Coghe F, Rabet L (2011) Measuring and modeling of low temperature Hopkinson tests. Procedia Engineering 10:1645-1650

32. Bergman TL (2011) Fundamentals of heat and mass transfer John Wiley \& Sons illustrated edition

33. Fukuhara M, Sanpei A (1993) Elastic moduli and internal frictions of Inconel 718 and Ti-6Al-4V as a function of temperature. J Mater Sci Lett 12:1122-1124

34. Nemat-Nasser S, Li Y (1998) Flow stress of f.c.c. polycrystals with application to OFHC $\mathrm{Cu}$. Acta Materialia 46(2):565577

Publisher's Note Springer Nature remains neutral with regard to jurisdictional claims in published maps and institutional affiliations. 


\section{Affiliations}

R.M. Quinn ${ }^{1}$ - L.H. Zhang ${ }^{2}$ - M.J. Cox ${ }^{3}$ D. Townsend ${ }^{2}$ - T. Cartwright ${ }^{3}$ - G. Aldrich-Smith A P.A. Hooper $^{1}$ J.P. Dear ${ }^{1}$ iD

R.M. Quinn

r.quinn16@ic.ac.uk

P.A. Hooper

paul.hooper@ic.ac.uk

1 Department of Mechanical Engineering, Imperial College London - City and Guilds Building, Exhibition Road, South Kensington, London, SW7 2AZ, UK

2 Impact Engineering, Department of Engineering Science, University of Oxford - Parks Road, Oxford, OX1 3PJ, UK

3 Materials, Analytical Science, Atomic Weapons

Establishment - AWE Plc, Aldermaston, Reading, RG7 4PR, UK 